last hundred years, and secured him, the modest apothecary of Köping, a place in the first rank of the men of science of all ages and of all countries."

In a succeeding paper I propose to give a sketch of the work of Scheele, and to return at the same time to the chemical labours of Bergman.

(To be continued.)

\section{THE TEMPERATURE OF SPACE AND ITS BEARING ON TERRESTRIAL PHYSICS}

$\mathrm{F} E W$ questions bearing directly on terrestrial physics have been so much overlooked as that of the temperature of stellar space, that is to say, the temperature which a thermometer would indicate if placed at the outer limits of our atmosphere and exposed to no other influence than that of radiation from the stars. Were we asked what was probably the mid-winter temperature of our island 11,700 years ago, when the winter solstice was in aphelion? we could not tell unless we knew the temperature of space. Again, without a knowledge of the temperature of space, it could not be ascertained how much the temperature of the North Atlantic and the air over it were affected by the Gulf Stream. We can determine the quantity of heat conveyed into the Atlantic by the stream, and compare it with the amount received by that area directly from the sun, but this alone does not enable us to say how much the temperature is raised by the heat conveyed. We know that the basin of the North Atlantic receives from the Gulf Stream a quantity of heat equal to about one-fourth that received from the sun, but unless we know the temperature of space we cannot say how much this one-fourth raises the temperature of the Atlantic. Suppose $56^{\circ}$ to be the temperature of that ocean: this is $517^{\circ}$ of absolute temperatures which is derived from three sources, viz. : (I) direct heat from the sun, (2) heat from the Gulf Stream, and (3) heat from the stars. Now unless we know what proportion the heat of the stars bears to that of the sun we have no means of knowing how much of the $517^{\circ}$ is due to the stars and how much to the sun or to the Gulf Stream.

M. Pouillet and Sir John Herschel are the only physicists who appear to have devoted attention to the problem. The former came to the conclusion that space has a temperature of $-142^{\circ} \mathrm{C}$. or $-224^{\circ} \mathrm{F}$., and the latter, following a different method of inquiry, arrived at nearly the same result, viz., that its temperatures is about $-239^{\circ} \mathrm{F}$.

Can space, however, really have so high a temperature as $-239^{\circ}$ ? Absolute zero is $-46 \mathrm{I}^{\circ}$. Space in this case would have an absolute temperature of $222^{\circ}$, and consequently our globe would be nearly as much indebted to the stars as to the sun for its heat. If so space must be enormously more transparent to heat rays than to light rays. If the heat of the stars be as feeble as their light, space cannot be much above absolute zero, and this is the opinion expressed to me a few weeks ago by one of the most eminent physicists of the day. Prof. Langley is also of this opinion, for he concludes that the amount of heat received from the sun is to that derived from space as much as four to one ; and consequently if our luminary were extinguished the temperature of our earth would fall to about $-360^{\circ} \mathrm{F}$.

It must be borne in mind that Pouillet's Memoir was written more than forty years ago, when the data available for the elucidating the subject were far more imperfect than now, especially as regards the influence of the atmosphere on radiant heat. For example, Pouillet comes to the conclusion that, owing to the fact of our atmosphere being less diathermanous to radiation from the earth than to radiation from the sun and the stars, were the sun extinguished the radiation of the stars would still maintain the surface of our globe at $-89^{\circ} \mathrm{C}$., or about $53^{\circ} \mathrm{C}$. above that of space. The experi- ments of Tyndall, however, show that the absorbing power of the atmosphere for heat-rays is due almost exclusively to the small quantity of aqueous vapour which it contains. It is evident, therefore, that but for the sun there would probably be no aqueous vapour, and consequently nothing to protect the earth from losing its heat by radiation. Deprived of solar heat, the surface of the ground would sink to about as low a temperature as that of stellar space, whatever that temperature may actually be.

But before we are able to answer the foregoing questions, and tell, for example, how much a given increase

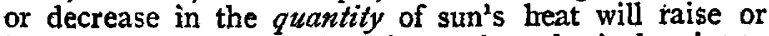
lower the temperature, there is another physical point to be determined, on which a considerable amount of uncertainty still exists. We must know in what way the temperature varies with the amount of heat received. In computing, say, the rise of temperature resulting from a great increase in the quantity of heat received, should we assume with Newton that it is proportional to the increase in the quantity of heat received, or should we adopt Dulong's and Petit's formula?

In estimating the extent to which the temperature of the air would be affected by a change in the sun's distance, I have hitherto adopted the former mode. This probably makes the change of temperature too great, while Dulong's and Petit's formula adopted by Mr. Hill (NATURE, vol. xx. p. 626), on the other hand, makes it too small. Dulong's and Petit's formula is an empirical one, which has been found to agree pretty closely with observation within ordinary limits, but we have no reason to assume that it will hold equally correct when applied to that of space, any more than we have to infer that it will do so in reference to temperature as high as that of the sun. When applied to determine the temperature of the sun from his rate of radiation, it completely breaks down, for it is found to give only a temperature of $2130^{\circ} \mathrm{F}$. (Amer. Four. Science, July, I870), or not much above that of an ordinary furnace.

But besides all this it is doubtful if it will hold true in the case of gases. From the experiments of Prof. Balfour Stewart (Trans. Edin. Roy. Soc., xxii.) on the radiation of glass plates of various thicknesses, it would seem to follow that the radiation of a material particle is probably proportionate to its absolute temperature, or, in other words, that it obeys Newton's law. Prof. Balfour Stewart found that the radiation of a thick plate of giass increases more rapidly than that of a thin plate as the temperature rises, and that, if we go on continually diminishing the thickness of the plate whose radiation at different temperatures we are ascertaining, we find that, as it grows thinner and thinner, the rate at which it radiates its heat as its temperature rises becomes less and less. In other words, as the plate grows thinner its rate of radiation becomes more and more proportionate to its absolute temperature. And we can hardly resist the conviction that if it were possible to go on diminishing the thickness of the plate till we reached a film so thin as to embrace but only one particle in its thickness, its rate of radiation would be proportionate to its temperature, or, in other words, it would obey Newton's law. Prof. Balfour Stewart's explanation is this : As all substances are more diathermanous for heat of high than low temperatures, when a body is at a low temperature only the exterior particles supply the radiation, the heat from the interior particles being all stopped by the exterior ones, while at a high temperature part of the heat from the interior is allowed to pass, thereby swelling the total radiation. But as the plate becomes thinner and thinner, the obstructions to interior radiation become less and less, and as these obstructions are greater for radiation at low than high temperatures, it necessarily follows that, by reducing the thickness of the plate, we assist radiation at low more than at high temperatures. 
If this be the true explanation why the radiation of bodies deviates from Newton's law, it should follow that in the case of gases where the particles stand at a considerable distance from one another, the obstruction to interior radiation must be far less than in a solid, and consequently that the rate at which a gas radiates its heat as its temperature rises, must increase more slowly than that of a solid substance. In other words, in the case of a gas, the rate of radiation must correspond more nearly to the absolute temperature than in that of a solid; and the less the density and volume of a gas, the more nearly will its rate of radiation agree with Newton's law. The obstruction to interior radiation into space must diminish as we ascend in the atmosphere, at the outer limits of which, where there is no obstruction, the rate of radiation should be pretty nearly proportional to the absolute temperature. May not this to a certain extent be the cause why the temperature of the air diminishes as we ascend?

If the foregoing considerations be correct, it ought to follow that a reduction in the amount of heat received from the sun, owing to an increase of his distance, should tend to produce a greater lowering effect on the temperature of the air than it does on the temperature of the solid ground. Taking, therefore, into consideration, the fact that space has probably a lower temperature than $-239^{\circ}$, and that the temperature of our climate is determined by the temperature of the air, it will follow that the error of assuming that the decrease of temperature is proportional to the decrease in the intensity of the sun's heat may not be great.

In estimating the extent to which the winter temperature is lowered by a great increase in the sun's distance there is another circumstance which must be taken into account. The lowering of the temperature tends to diminish the amount of aqueous vapour contained in the air, and this in turn tends to lower the temperature by allowing the air to throw off its heat more freely into space.

JAMES CROLL

THE RUSSIAN GEOGRAPHICAL SOCIETY

$\mathrm{T} T$ is no easy matter to render an account of the pro1 ceedings and publications of the "Imperial Russian Geographical Society." So numerous are its sections, and so prolific is each of them, that to master the whole of the information yearly made available by them would be no easy task, even for a reader possessing the amount of leisure which most Russians enjoy. Some of its volumes, however, are intended merely as works of reference, books which are not meant to be read through, but which serve as useful storehouses of facts and figures. Of such a nature is the huge collection now before us of Pistsovuiya knigi, the rent-rolls, as it were, of the estates of ecclesiastical and lay proprietors of the soil in the sixteenth century. Some idea of the magnitude of the work may be gained from the fact that the second part alone of its first volume contains 1,598 large and closely printed pages. As a general rule, the publications of the Society are of no use to foreigners who are unacquainted with Russian. But there are a few exceptions, such as the monograph by Prof. Oswald Heer, of Zurich, on the fossil flora of the coal-fields of East Siberia. In I859 a rich collection of fossil plants was made in the Amur district by $F$. Schmidt, but it was burnt in the great fire of Blagoveshensk the year after. In 1862 a fresh collection was made, and submitted to Prof. Heer. The results of his investigations are given in the second division of "the geological part" of the third volume of "the physical section" of the Records (Trudi) of the "Siberian Expedition" of the Society, under the title of the "Jurassic Flora of the Irkutsk Government and the Amur Territory." The greater part of the text is in Russian. But as the descriptions are in Latin, and they are accompanied by thirty-one quarto plates, printed at Winterthur, the book is available for Western scholars. The expedition of the late A. Tchekanovsky to the Lena in I875, says the editor, F. Schmidt, in his preface, has contributed new and important additions to our knowledge of the Jurassic flora of Siberia. "The Jurassic plants collected around Bulun and Ayakit, Lower Lena, serve as a link between the Jurassic flora of South-East Siberia and the same flora of the Spitzbergen Isles, and prove the unity and comparative uniformity of the Jurassic flora over a great part of the northern hemisphere, namely from Spitzbergen to England (Yorkshire) and beyond the Lena to the Irkutsk Government and the Amur." Much valuable information about Siberia is given also in the voluminous supplements to Ritter's "Asia," "serving as a continuation of Ritter's work, based upon materials rendered available since $1832 . "$

Among the subjects treated at greatest length in the Transactions (Zapiski) of the Ethnographical Section of the Society are "The Shores of the Frozen and White Seas," "The Church Calendar of the Common People," and the "Popular Juridical Customs of the Russian Empire." The treatise on the first gives a full account of the various tribes inhabiting the inhospitable northern shores. In speaking of the Samoyeds, it may be worthy of remark, the author does not even so much as allude to the absurd explanation (dear to many English minds) of their name as meaning cannibals. Lyudoyed, in Russian (from lyudi, men, and yest', to eat), signifies a cannibal. A false analogy has resolved Samoyed into the same meaning. If it meant anything in Russian, it would mean a "selfeater," whatever that might be. Russian philologists explain it in different ways. Some, as Lerberg, consider it a Russian word, corrupted from Semgo-yed, a salmoneater. Byelyavsky says that the Samoyeds employ, in speaking of each other, a common tribal or family designation Khasovo, from Khaz, self (in Russian sam) and ovo, one (in Russian odin). From these Russian equivalents of the Samoyed words, sprang, he supposes, a designation Sam-odin or Sam-yedin. In some old documents the Samoyeds are called Suiroyadtsui, from their habit of eating raw (suiroe) meat. But there seems to be no reason for supposing that the two names have any connection. Much more probable is the surmise that the word is of Finnish origin, the land belonging to some Ugrian neighbours of the Samoyeds having been called Samoyanda or Samoyedna, from which the Russians formed the name Samoyed. The Calendar gives a detailed account of the Saints' days observed by the Russiar peasants, and of the various superstitions and rites connected with them. It begins with September, which was officially chosen as the first month at the Council of Moscow in 1342 . In ancient days March was among the Russians, as it was among the Israelites, the commencement of the new year. Its modern name, Mart, was derived from Rome through Byzantium; the heathen Slavs knew it as Sukhy, "the Dry," or Berezozol, from its effect on the bereza or birch-tree.

The volume devoted to the juridical institutions of the common people, their civil and criminal law courts, is full of interest; and the information it contains is thoroughly trustworthy, having been carefully collected and sifted by the members of a Commission appointed for the purpose in 1876 . It embraces not only the village-jurisprudence of the Russians themselves, but also that of the strangers within their gates, and the wild tribes of their outlying provinces. Ot great interest also are the numerous volumes of Reports (trudui) issued by the members of the Ethnographical-Statistical Commission appointed to explore the western provinces of Russia. The seven large volumes devoted to the southwestern governments give an exhaustive account of Little-Russia, entering into most minute detail; concerning the physical and moral character of the inhabitants of that part of the empire, between whom and the 